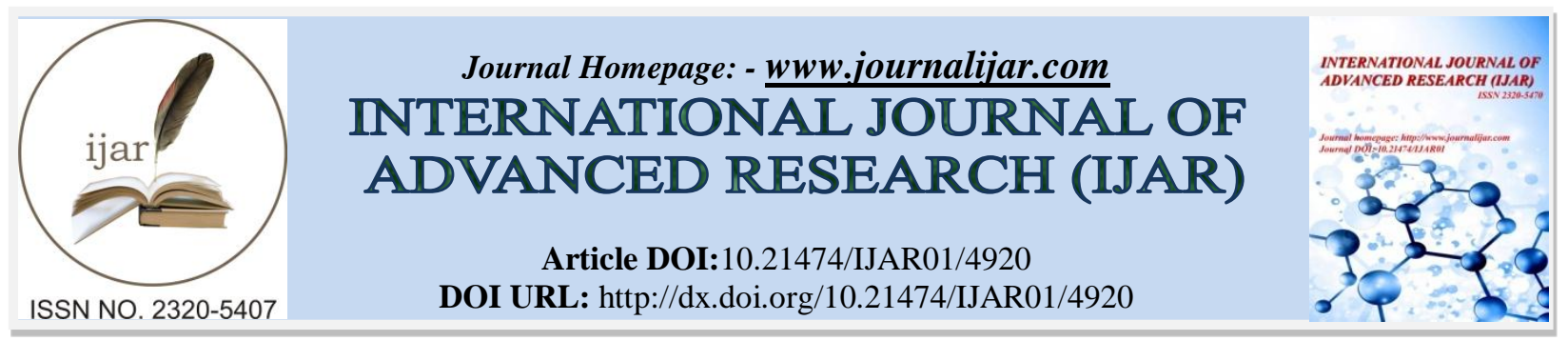

RESEARCH ARTICLE

\title{
EXTRACTION OF OIL FROM DATURA STRAMONIUM SEEDS AS POTENTIAL FEED-STOCK FOR BIO-DIESEL PRODUCTION.
}

\section{Banyaladzi D. Paphane ${ }^{1}$, Ruth Gontse ${ }^{1}$, Thapelo Francis ${ }^{1}$ and Kethabile Sonno ${ }^{2}$.}

1. Department of Basic Sciences, Botswana University of Agriculture and Natural Resources, Private Bag 0027, Gaborone, Botswana.

2. Department of Food Science and Technology, Botswana University of Agriculture and Natural Resources, Private Bag 0027, Gaborone, Botswana.

\section{Manuscript Info}

Manuscript History

Received: 22 May 2017

Final Accepted: 24 June 2017

Published: July 2017

\section{Abstract}

Energy demand is increasing due to the expanding population growth in Botswana and the world at large. It has become apparent that biodiesel is destined to make a substantial contribution to the future energy demands of the domestic and industrial economies. Non-edible plant oils which are known as the second generation feed-stocks can be considered as promising substitutions for traditional edible food crops for the production of bio-diesel. The use of non-edible plant oils is very significant because of the tremendous demand for edible oils as food source. Moreover, edible oils' feedstock costs are far expensive to be used as fuel. Therefore, production of bio-diesel from non-edible oils is an effective way to overcome all the associated problems with edible oils. However, the potential of converting non-edible oil into bio-diesel must be well examined as the physical and chemical properties might differ from that of edible oils, hence the need for this research.

Copy Right, IJAR, 2017,. All rights reserved.

\section{Introduction:-}

Biodiesel is the product obtained when vegetable oils or animal fat is chemically reacted with an alcohol to produce fatty acid alkyl esters, Basumatary, 2013. Manufacturing biodiesel from non-edible oil plants is relatively easy and possesses many environmental benefits. Studies have indicated that the use of waste cooking oil and non-edible oil for biodiesel production are cheaper compared to using edible oils such as sunflower oils and canola oils, Sruthi 2013. The use of plant oils for biodiesel production is described as a 'renewable fuel' as it does not add any extra carbon dioxide gas to the atmosphere, as opposed to fossil fuels, which cause changes in the atmosphere, Mulimani et al ., 2012. Currently, more than 95\% biodiesel are produced from edible oil feedstock such as soya bean oil, sunflower oil, niger oil, rapeseed oil, palm oil, linseed oil, canola seed oil and sesame oil. This led to decreased food supply for communities as edible oils are used for bio-diesel production.

Many researchers have initiated work on the use of low cost non-edible oils as alternative feedstock for biodiesel production. Among non-edible oil feedstock, seeds of castor and jatropha, and microalgae oil have proved to be some of the highly promising reliable sources having high seed oil content, Sruthi, 2013. Algae are an economical choice for biodiesel production, because of its availability and low cost. The use of certain feed-stocks for biofuels

Corresponding Author:- Banyaladzi D. Paphane.

Address:- Department of Basic Sciences, Botswana University of Agriculture and Natural Resources, 
production also results in the co-production of animal feed. Globally, these animal feed co-products are growing in volume and importance.

The advantages of non-edible plants in biofuel production are that they can be cultivated along the borders and bunds of crop lands, habitations, road sides and the unutilized barren lands. Households can also grow non-edible oil seed plants in the farm vicinity, on borders, bunds, and backyards. The production of biodiesel from non-edible sources is very important hence their characterization is necessary towards achieving and improving the quality of the renewable fuel and also enhances domestic energy security, spur economic development and reduce emissions of greenhouse gases (GHG) and other pollutants. This study is investigating the potential of a Botswana indigenous, non-edible, seed bearing plant, Datura stramonium, commonly known locally as mokhure plant for the production of bio-diesel.

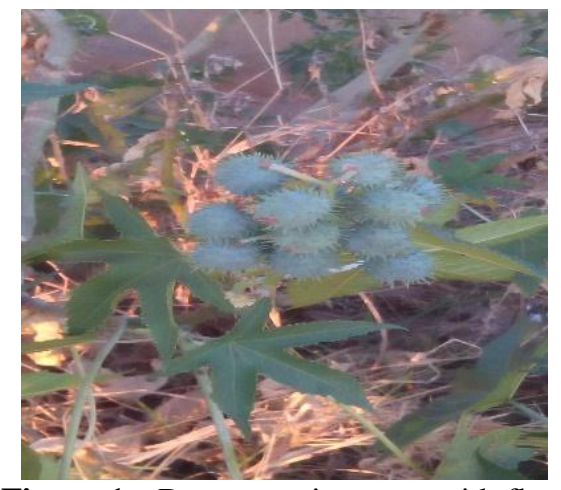

Figure.1:- D. stramonium tree with flowers\&pods

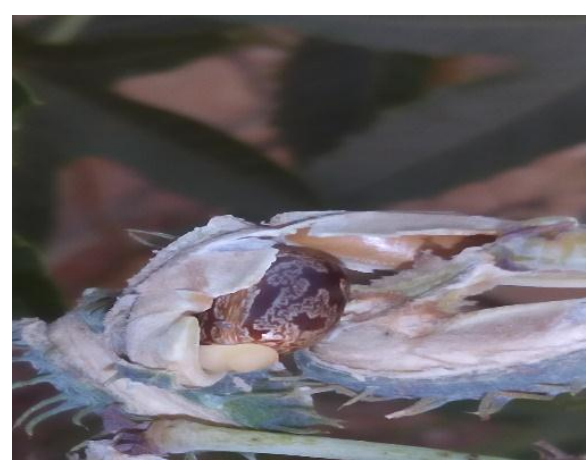

Figure.2:- D. stramonium pod with seeds

Datura stramonium is a foul-smelling, erect, annual, freely branching herb that forms a bush up to 60 to $150 \mathrm{~cm}$. The root is long, thick, fibrous and white. The stem is stout, erect, leafy, smooth, and pale yellow-green. The stem forks off repeatedly into branches and each fork forms a leaf and a single, erect flower. The leaves are about 8 to $20 \mathrm{~cm}$ long, smooth, toothed, soft, and irregularly undulated. The upper surface of the leaves is a darker green, and the bottom is a light green. The leaves have a bitter and nauseating taste, which is imparted to extracts of the herb, and remains even after the leaves have been dried, Mairura, 2008.

Datura stramonium has fragrant flowers that are trumpet-shaped, white to creamy or violet, 6 to $9 \mathrm{~cm}$ long, and grow on short stems from either the axils of the leaves or the places where the branches fork. The calyx is long and tubular, swollen at the bottom, and sharply angled, surmounted by five sharp teeth, Kirby, 2013. The corolla, which is folded and only partially open, is white, funnel-shaped, and has prominent ribs. The flowers open at night, emitting a pleasant fragrance, and are fed upon by nocturnal moths. The egg-shaped seed capsule is 3 to $8 \mathrm{~cm}$ in diameter and either covered with spines or bald. At maturity, it splits into four chambers, each with dozens of small, black seeds.

All parts of Datura plants contain dangerous levels of the tropane alkaloids atropine, hyoscyamine, and scopolamine, which are classified as deliriants, or anticholinergics. The risk of fatal overdose is high among uninformed users, and many hospitalizations occur amongst recreational users who ingest the plant for its psychoactive effects. Datura intoxication typically produces delirium (as contrasted to hallucination), hyperthermia, tachycardia, bizarre behavior, and severe mydriasis with resultant painful photophobia that can last several days. Pronounced amnesia is another commonly reported effect. The onset of symptoms generally occurs around 30 to 60 minutes after ingesting the herb. These symptoms generally last from 24 to 48 hours, but have been reported in some cases to last as long as two weeks, Mairura, 2008.

\section{Uses:-}

Datura leaves are used to treat pain. The paste of roasted leaves is applied over the area to relieve pain. It is used as herbal medicine, especially in case of asthma and bone setting. It is also is used to treat spasm of bronchitis in asthma, Setshogo, 2005. The ethanol extract of Datura is used as repellent against larva and mosquito. The leaves of Datura are used to treat heart problems like palpitations and hypertension. Datura leaves juice is used to treat 
earache. Boils can also be overcome by applying Datura leaves as poultice. The leaves of Datura are good to relieve headache. The vapor of Datura leaves infusion is used to relieve arthritis such as rheumatism and gout.

\section{Ecology:-}

Datura stramonium occurs in open locations such as grassland, roadsides, waste places, scrub vegetation and open forest. It tolerates various soil types but prefers clay or loamy soils. Datura stramoniumis frost sensitive. In Botswana, Datura stramonium is considered a serious weed in crops; elsewhere it is considered a weed in waste land. Control is difficult as Datura stramonium is resistant to most commonly used herbicides.

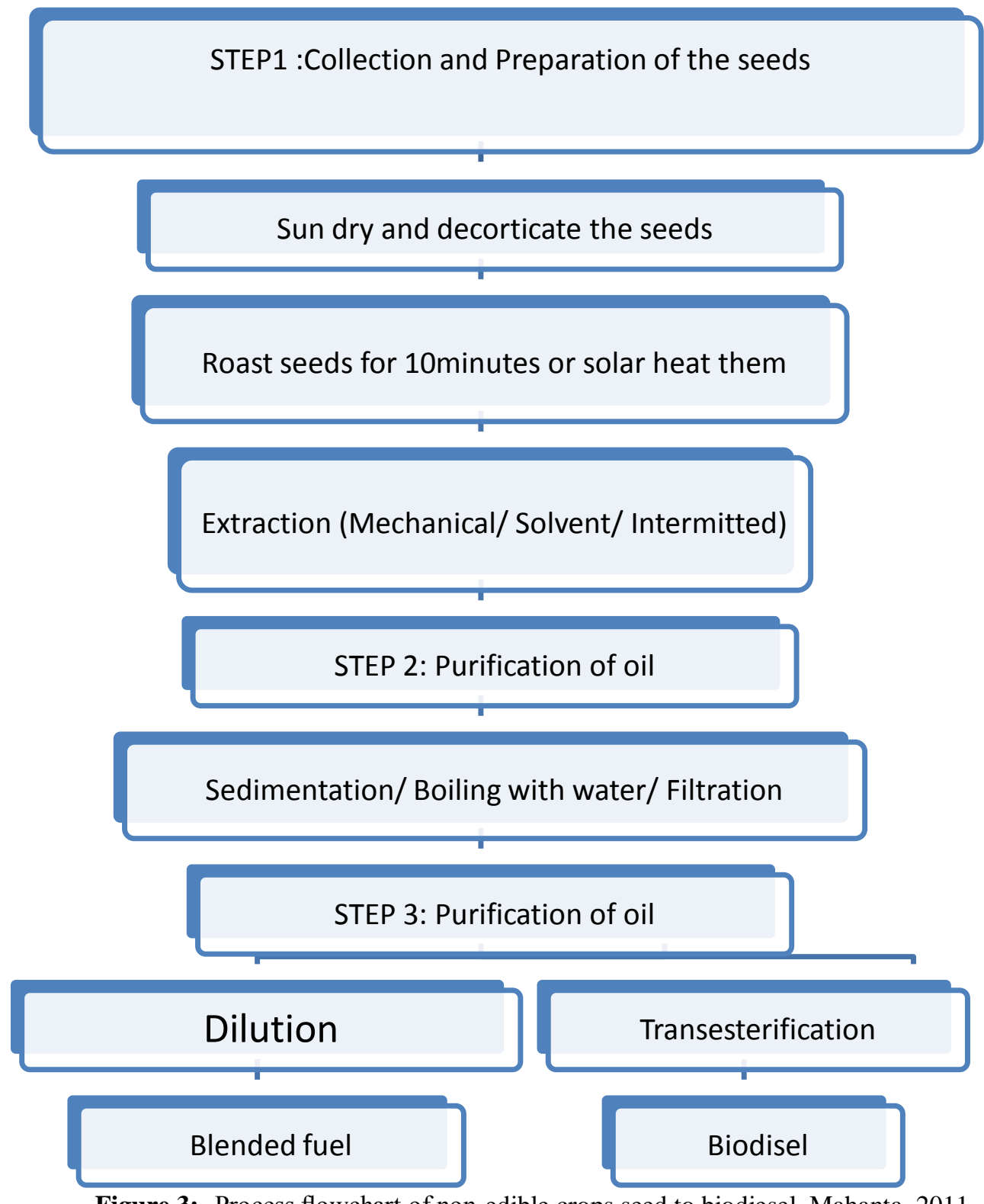

Figure 3:- Process flowchart of non-edible crops seed to biodiesel, Mahanta, 2011.

\section{Methodology:-}

Sample collection:-

The seeds for Datura stramonium were collected at Tumasera Village, in the Central District of Botswana and identified at the Botswana University of Agriculture and Natural resources herbarium. 


\section{Procedure:-}

The Datura stramonium seed samples were decorticated and then crushed to increase surface area using a pestle and mortar. The total sample was weighed and a mass of $150.18 \mathrm{~g}$ was obtained. From there, oil was extracted using the solvent extraction method which entails the use of a soxhlet extraction unit for a total of 6hours in n-hexane. The solution was then taken to the rotary evaporator in order to separate the solvent (n-hexane) from the oil. A temperature was set at $42^{\circ} \mathrm{C}$ under vacuum with $20 \mathrm{rpm}$. A total volume of $50 \mathrm{~mL}$ oil was yielded. Further analyses which will be explained next were performed on the oil.

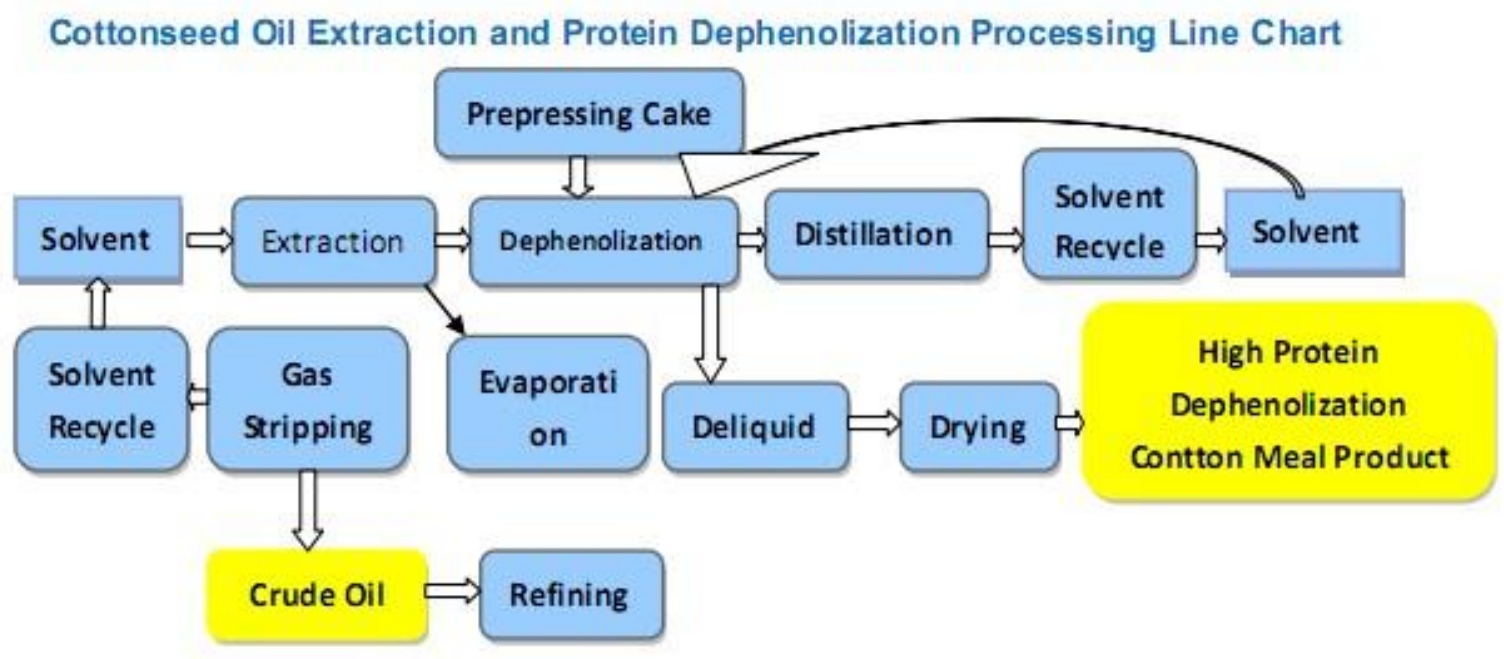

Figure 4:- Solvent Extraction Flow Diagram, http://www.oilmachineworld.com/cottonseed-oil-extractionmachine.html. 


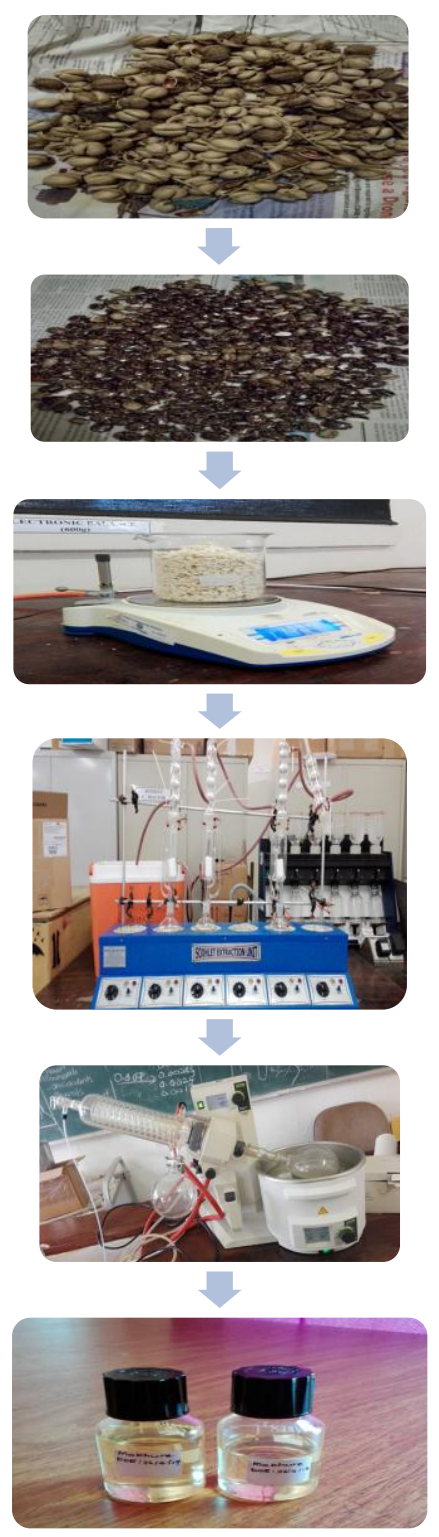

Test for unsaturation:-

Figure 5:- Process of oil extraction, Datura stramonium oil extraction.

$1 \mathrm{ml}$ of oil was placed in 3 different test tubes and then labeled according to the test to be performed. 5 drops of bromine, potassium permanganate and sulfuric acid were placed in each of the test tubes and gently mixed under a fume hood. The results were then recorded.

\section{Results and discussions:-}

Test for Unsaturation:-

1. The Bayer's Test:-

The purple color of potassium permanganate changed to brown.

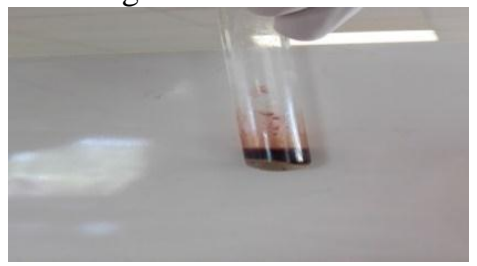

Figure 6:- Reaction of oil with potassium permanganate $\left(\mathrm{KMnO}_{4}\right)$. 


\section{Reactions with Bromine:-}

After the mixture was gently shook under the fume hood, it decolorized from a brownish color to a colorless color.

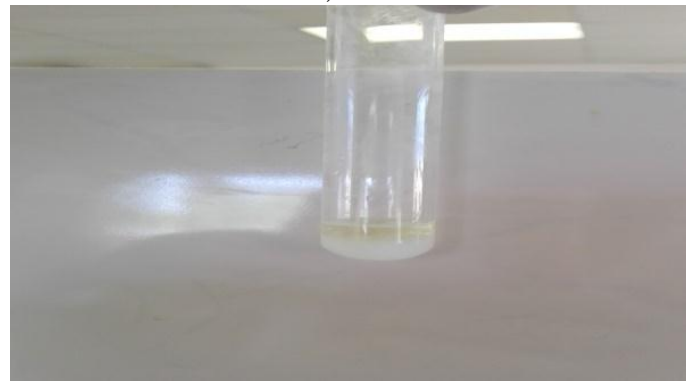

Figure 7:- Reaction of oil with bromine $\left(\mathrm{Br}_{2}\right)$.

3. Reaction with sulphuric acid:-

The color of the mixture turned brown.

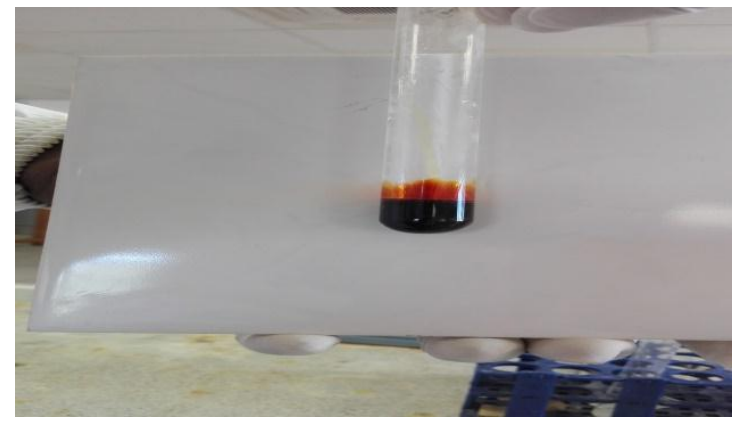

Figure 8:- Reaction of oil with sulfuric acid $\left(\mathrm{H}_{2} \mathrm{SO}_{4}\right)$.

Table 1:- Comparison of Datura stramonium with non-edible seed oil plants, Olasheu, 2015.

\begin{tabular}{|l|l|l|l|}
\hline & Datura stramonium & Jatropha curcas & Cynara curdunculus \\
\hline Average yield $(\%)$ & $33.29 \pm 0.02$ & 34.4 & 25 \\
\hline Density $(\mathrm{g} / \mathrm{mL})$ & $0.9633 \pm 0.003$ & 0.93292 & $0.64-0.93$ \\
\hline Saturation & Unsaturated & Unsaturated & Unsaturated \\
\hline
\end{tabular}

\section{Yield and Density:-}

The percentage oil yield of this experiment is $33.29 \%$ which is quite high. The tree indicates great potential in the oil production industry. In comparison to the non-edible and edible seed oil plants (Table 1), Datura stramonium oil production is quiet similar which is a positive discovery as the aim is to promote and encourage the use of nonedible seed oil for production of biodiesel instead of edible ones.

The density of the Datura stramonium oil is high $(0.9633 \mathrm{~g} / \mathrm{ml})$ which is comparable with other oils from known non-edible seeds (Table1).

\section{The Baeyer Test:-}

The Baeyer reagent is a cold dilute aqueous solution of potassium permanganate which is a deep purple color. Potassium permanganate does not react with saturated compounds because they contain single bonds. When it is added to saturated oils the purple color does not change. It changes color when added to unsaturated compounds, this means that the compound has double bonds within the carbon chain and can be further broken down to form single bonds. Datura stramonium oil showed a change in color (Figure 10) indicating unsaturation.

\section{Reaction with bromine:-}

Bromine $\left(\mathrm{Br}_{2}\right)$ can also be used to test for unsaturation. An addition reaction happens at the carbon-carbon double bond, producing a dibromo compound. The observed change is that the bromine is decolorized. As indicated by Figure 11, the oil as with other existing plants show that the oil is unsaturated, just like with the test using potassium permanganate. The change in color from brown to colorless indicates presence of double bonds. Saturated compounds do not have a carbon-carbon double bond, so they cannot react with bromine in this way. 


\section{Reaction with sulfuric acid:-}

A similar case is presented with this test as there is a change in color to brown as indicted in Figure 12. This again indicates unsaturation. The test is very quick and can present danger, ensure it takes place under fume hood to reduce any dangers. Comparing this result with other edible and non-edible oils that are used for biodiesel, it shows similarity and potential.

\section{Conclusion:-}

The study shows that Botswana is more than capable of producing good quality oil from various plants that could be used for different purposes, most importantly to improve the living standards of its citizens by engaging in such studies that can prove very economical. The Datura stramonium tree shows great potential in the oil extraction industry and can be used for different purposes. The use of non-edible plants for oil extraction could also help relieve the pressure on the edible plants as they have so many uses already thus reducing them from becoming extinct or reduction in their population.

\section{References:-}

1. Akkurt, R., Vinegar, H., Tutunjian, P., and Guillory, A. NMR logging of natural gas reservoirs: The Log Analyst, (1996) 37, no. 6, p. $33-42$.

2. Basumatary, S. Biodiesel Production: Journal of Chemical, Biological and Physical Sciences, (2013), 3(1), 551558.

3. Brummitt, R.K., Chikuni, A.C., Lock, J.M. \&Polhill, R.M. (2007). Leguminosae Subfamily Caesalpinioideae Flora Zambesiaca 3(2), 36 - 39.

4. Carvalhoa C.R., Clarindoa W.R., Praça M.M., Araújoa F.S., Carelsand N.. Genome size, base composition and karyotype of Jatropha curcas L., an important biofuel plant, Plant Science , (2008), 174, 613-617)

5. pubs.rsc.org/en/content/articlehtml/2009/gc/b810423a

6. Devan PK, and Mahalakshmi NV. Study of the performance, emission and combustion characteristics of a diesel engine using poon oil-based fuels. Fuel Processing Technology (2009); 90(4):513-9.

7. http://www.worldagroforestry.org/sites/treedbs/treedatabases.asp Accessed on 02/05/2017

8. Mahanta P., and Shrivastava A. Technology development of bio-diesel as an energy alternative; 2011 [cited 12 March 2011]

9. Mairura F. S.and Setshogo M. P. Daturastramonium L. In: Schmelzer GH, Gurib-Fakim A (Editors) (2008). Plant Resources of Tropical Africa 11(1). Medicinal Plant 1. PROTA Foundation, Wageningen, Netherlands / Backhuys Publishers, Leiden, Netherlands/CTA, Wageningen, Netherlands, $221-225$.

10. making-biodiesel-books.com/about-algae/algae-oil-extractionAccessed on 16/11/2016

11. Olasheu, T.I, Adebiyi, K.A, Durowoju, M.O, and Odesanya, K.O, Determination of Some Physical Properties of Jatropha (Jatropha Curcas), International Journal of Engineering Research, Oil, (2015), 4(6), 331-338

12. Sruthi, K., Kumar, R. andShirisha, G. Determination of physico-chemical properties of Castor Biodiesel: A potential alternate to Conventional Diesel. International Journal of Advanced Research in Engineering and Technology, (2013), 4(3), 101-107.

13. Watt JM, Breyer-Brandwijk. 1962. Medicinal and poisonous plants of southern and eastern Africa. E \& S Livingstone Ltd. 